\title{
Free Radical Scavenging Potency of Dihydroxybenzoic Acids
}

\author{
Dejan Milenković, ${ }^{1}$ Jelena Đorović, ${ }^{1}$ Svetlana Jeremić, ${ }^{2}$ Jasmina M. Dimitrić Marković, ${ }^{3}$ \\ Edina H. Avdović, ${ }^{2}$ and Zoran Markovici ${ }^{1,2}$ \\ ${ }^{1}$ Bioengineering Research and Development Center, 34000 Kragujevac, Serbia \\ ${ }^{2}$ Department of Chemical-Technological Sciences, State University of Novi Pazar, Vuka Karadžića bb, 36300 Novi Pazar, Serbia \\ ${ }^{3}$ Faculty of Physical Chemistry, University of Belgrade, Studentski trg 12-16, 11000 Belgrade, Serbia
}

Correspondence should be addressed to Dejan Milenković; deki82@kg.ac.rs

Received 2 January 2017; Accepted 9 February 2017; Published 26 February 2017

Academic Editor: Yuan-Pern Lee

\begin{abstract}
Copyright (C) 2017 Dejan Milenković et al. This is an open access article distributed under the Creative Commons Attribution License, which permits unrestricted use, distribution, and reproduction in any medium, provided the original work is properly cited.

In order to evaluate the free radical scavenging potency of dihydroxybenzoic acids (DHBAs) the Density Functional Theory (DFT) was used. The M05-2X/6-311++G(d,p) and B3LYP-D2/6-311++G(d,p) theoretical models were applied. Three possible antioxidant mechanisms were examined: hydrogen atom transfer (HAT), single-electron transfer followed by proton transfer (SET-PT), and sequential proton loss electron transfer (SPLET) mechanisms. All of these mechanisms have been studied in nonpolar (benzene and pentylethanoate) and polar solvents (water) using an implicit solvation model (SMD). The following thermodynamic quantities related to these mechanisms were calculated: bond dissociation enthalpy (BDE), ionization potential (IP), and proton affinity (PA). The obtained results indicated the HAT mechanism as the most favourable reaction pathway for antioxidative action of DHBAs in benzene. On the other hand, SPLET is indicated as predominant reaction mechanism in polar solvent. The SET-PT mechanism was not favourable reaction path for antioxidative action in any of the solvents under investigation.
\end{abstract}

\section{Introduction}

Oxidative stress plays an important role in the pathogenesis of many diseases [1-5]. To neutralize the damaging effect of free radicals, the organisms often use some external factors including the dietary substances, such as phenolics, which can help in prevention of free radical damage. These substances constitute complex antioxidant defence systems. Phenolic acids are the group of the naturally occurring compounds which, besides one carboxylic acid functionality, have the common structural features as all phenolics: an aromatic ring bearing one or more hydroxyl substituents. There are two types of the phenolic acids: hydroxycinnamic (HCA) and hydroxybenzoic acids (HBA) [6, 7]. They are constituents of almost all vegetables, fruits, and grains. They can be found in the free state, but most commonly they are occurring in plant materials linked through esters, ethers, or as structural components of the cellulose, proteins, and lignins [8-10]. There is some evidence affirming multiple roles and functions of the phenolic acids and indicating these compounds as involved in processes such as the protein synthesis, nutrient uptake, enzyme activity, photosynthesis, and allelopathy [11-13]. There are also a number of the epidemiological investigations [14-17] which confirm a possible connection between the consumption of food containing phenolics and the reduced risk of developing some disorders, including cancer and cardiovascular diseases. However their in vivo role is still unknown.

It has been proposed that the antioxidant activity of HBA depends on the number of hydroxyl groups in a molecule [18] and that it increases following the order: monohydroxy, dihydroxy, and trihydroxy, respectively [19]. Dihydroxybenzoic acids (DHBA) are a subclass of hydroxybenzoic acids possessing two hydroxyl groups whose relative position determines the properties of molecules. There are some experimental evidences which generally confirm good antioxidant activity of DHBAs [20, 21], especially indicating good scavenging potency of 3,4-DHBA and 2,3-DHBA. Protocatechuic acid (3,4-DHBA) is a strong antiradical and antioxidant agent which inhibits the chemical carcinogenesis and show 
protection against the hydroperoxide-induced toxicity [22]. Also, a few positive health attributes of 3,4-DHBA such as antibacterial [23], antimutagenic [24], anti-inflammatory, anticoagulatory [25], and antihyperglycemic [26] actions have been reported. Although all these compounds can be found in natural products there are certain findings which implicate the nonenzymatic production of 2,3-DHBA (pyrocatehuic acid), which proceeds upon trapping the hydroxyl radical by salicylic acid [27]. Moreover, pyrocatehuic acid may act as a metabolite of dioxygenases [28].

As mentioned, the antioxidant ability of the phenolic acids is greatly influenced by the number and the relative position of the hydroxyl groups in the ring. It has been also suggested that the proximity of the hydroxyl groups to the acid moiety promotes the hydrogen atom transfer from the phenolic acid ( $\mathrm{PhO}-\mathrm{H})$ to the radical specie. In the radical scavenging mechanisms the reactive radical specie is inactivated by accepting a hydrogen atom from a hydroxyl group of the phenolic acid. Phenolic acids can scavenge free radicals through three competitive mechanisms, which are generally influenced by the reaction conditions. The suggested mechanisms are hydrogen atom transfer (HAT, (1)), single-electron transfer followed by proton transfer (SET-PT, (2a) and (2b)), and sequential proton loss electron transfer (SPLET, (3a) and (3b)) [29-36]:

$$
\begin{aligned}
& \mathrm{Ph}-\mathrm{OH} \longrightarrow \mathrm{Ph}-\mathrm{O}^{\bullet}+\mathrm{H}^{\bullet} \\
& \mathrm{Ph}-\mathrm{OH} \longrightarrow \mathrm{PhOH}^{+\bullet}+\mathrm{e}^{-} \\
& \mathrm{Ph}-\mathrm{OH}^{+\bullet} \longrightarrow \mathrm{Ph}-\mathrm{O}^{\bullet}+\mathrm{H}^{+} \\
& \mathrm{Ph}-\mathrm{OH} \longrightarrow \mathrm{Ph}^{-} \mathrm{O}^{-}+\mathrm{H}^{+} \\
& \mathrm{Ph}^{-} \mathrm{O}^{-} \longrightarrow \mathrm{Ph}-\mathrm{O}^{\bullet}+\mathrm{e}^{-}
\end{aligned}
$$

From the presented equations, it is clear that all these mechanisms have the same net result: formation of the corresponding phenoxyl radical which is more stable and less reactive than the free radical specie. The antioxidative mechanisms mentioned above are characterized with the thermodynamic parameters: bond dissociation enthalpy (BDE) related to (1), ionization potential (IP) related to (2a), proton dissociation enthalpy (PDE) related to (2b), proton affinity (PA) related to (3a), and electron transfer enthalpy (ETE) related to (3b).

In this paper, we aimed to provide thermodynamical parameters, related to the antiradical mechanism, that can implicate the antioxidant activity of six DHBAs: 2,3-dihydroxybenzoic acid (2-pyrocatechuic acid or hypogallic acid); 2,4-dihydroxybenzoic acid ( $\beta$-resorcylic acid); 2,5 -dihydroxybenzoic acid (gentisic acid); 2,6-dihydroxybenzoic acid (gamma-resorcylic acid or 2,6-resorcylic acid); 3,4dihydroxybenzoic acid (protocatechuic acid), and 3,5-dihydroxybenzoic acid ( $\alpha$-resorcylic acid) (Figure 1$)$.

\section{Methodology Section}

All calculations were performed using Gaussian 09 program package [37], and two levels of theory were applied. The

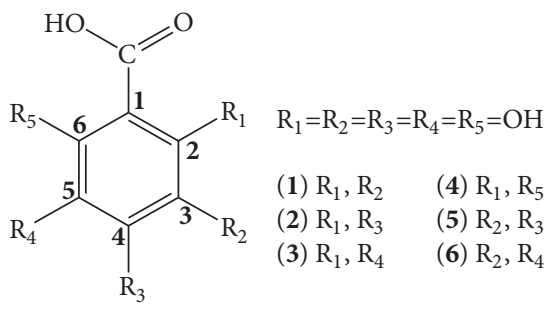

FIgURE 1: Structural formulas of the examined dihydroxybenzoic acids $(1,2,3,4,5$, and 6$)$ with atom labeling indicated and their trivial names.

optimized geometries of the investigated dihydroxybenzoic acids and the corresponding radicals, anions, and radical cations were obtained by M05-2X method, in combination with $6-311++\mathrm{G}(\mathrm{d}, \mathrm{p})$ basis set $[38,39]$. This hybrid functional, initially developed by Truhlar group [38], gives satisfactory results in the thermochemical and kinetic calculations and has been used widely by numerous authors [40-44].

The other applied method is B3LYP-D2, developed by Grimme [45, 46]. This functional can be efficiently coupled with any existing DFT method. It is proved that this method describes the interatomic interactions at short and medium distances $(\leq 5 \AA)$ reliably and more accurately than the traditional DFT methods. For including a long-range dispersion contributions to the computed DFT total energy and gradients at the B3LYP level of theory [47, 48], Grimme [46] and Bayach et al. [49] used an atom-atom additive damped empirical potential of the form $-f(R) C_{6} / R^{6}$ :

$$
E_{\mathrm{B} 3 \mathrm{LYP}-\mathrm{D} 2}=E_{\mathrm{B} 3 \mathrm{LYP}}-E_{\text {Disp }},
$$

where $C_{6}$ is the dispersion coefficient for the pair of atoms, $R$ is the interatomic distance between atoms, and $E_{\text {Disp }}$ is the empirical term. Both M05-2X and B3LYP-D2 methods were chosen, primarily because of being widely used and secondly because these methods describe very well the interatomic interactions at short and medium distances. These methods are more reliable and accurate than traditional density function methods.

Potential energy minima for all the optimized species are verified by the absence of the imaginary frequencies. Influence of water, pentylethanoate, and benzene was estimated using SMD solvation model [50]. The SMD continuum model allows the quantum mechanical approach in studying the interactions of the solvated molecules. The selected solvents enable investigating the behaviour of the molecules in polar and nonpolar environment. The delocalization effects were assessed within the NBO analysis framework [51].

The thermodynamical parameters relevant for the investigated antioxidative mechanisms (BDE, IP, PDE, PA, and ETE) were calculated from total enthalpies of the optimized species using the following equations:

$$
\begin{aligned}
\mathrm{BDE} & =H\left(\mathrm{Ph}-\mathrm{O}^{\bullet}\right)+H\left(\mathrm{H}^{\bullet}\right)-H(\mathrm{Ph}-\mathrm{OH}) \\
\mathrm{IP} & =H\left(\mathrm{Ph}^{-} \mathrm{OH}^{\bullet+}\right)+H\left(\mathrm{e}^{-}\right)-H(\mathrm{Ph}-\mathrm{OH})
\end{aligned}
$$




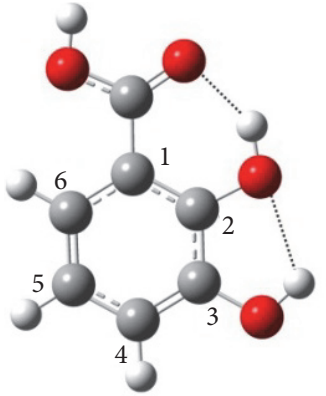

1

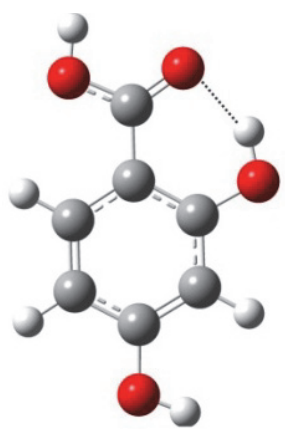

2

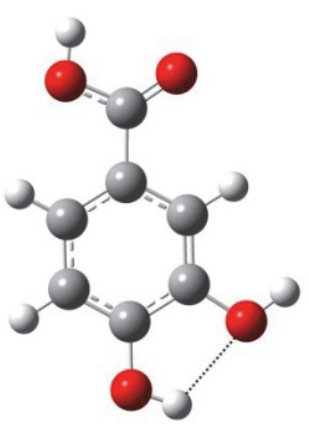

5

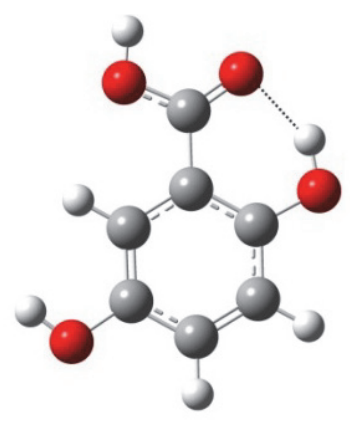

3

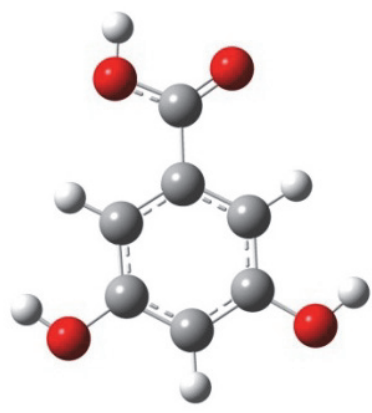

6

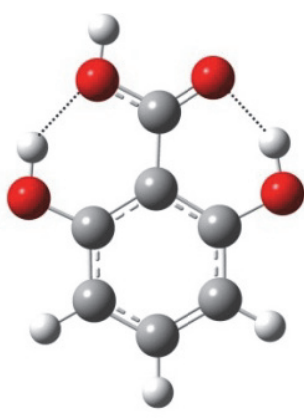

4

FIGURE 2: The most stable structures of the examined DHBAs.

$$
\begin{aligned}
\mathrm{PDE} & =H\left(\mathrm{Ph}-\mathrm{O}^{\bullet}\right)+H\left(\mathrm{H}^{+}\right)-H\left(\mathrm{Ph}-\mathrm{OH}^{\bullet+}\right) \\
\mathrm{PA} & =H\left(\mathrm{Ph}-\mathrm{O}^{-}\right)+H\left(\mathrm{H}^{+}\right)-H(\mathrm{Ph}-\mathrm{OH}) \\
\mathrm{ETE} & =H\left(\mathrm{Ph}-\mathrm{O}^{\bullet}\right)+H\left(\mathrm{e}^{-}\right)-H\left(\mathrm{Ph}-\mathrm{O}^{-}\right)
\end{aligned}
$$

The recommended values of the solvation enthalpies of the protons and electrons were taken from the literature [52]. The reaction enthalpies were calculated at $298.15 \mathrm{~K}$, with the temperature effects not taken into the account.

\section{Results and Discussion}

The conformational analysis of DHBAs was carried out. For this purpose, different conformations were obtained in the following way. First, two structures of each DHBA were constructed by placing the carboxyl group into two extreme positions (rotation around the C-C bond by $180^{\circ}$ ). Then, each of these structures was analysed by different orientations of hydrogen atom (antiperiplanar and synperiplanar) of different hydroxyl groups. All the rotamers of DHBAs are presented in Supplementary Material available online at https://doi.org/10.1155/2017/5936239 (Figures S1S6). The tables shown in Supplementary Material (Tables S1S6) indicate the energy differences between the investigated rotamers of all the compounds under investigation. The most stable structures are presented in Figure 2.

The structures of the all DHBAs presented in Figure 2 are planar and have at least one internal hydrogen bond (IHB). Namely, compounds which possess the hydroxyl group in position $\mathrm{C} 2$ have IHB between hydrogen atom of the hydroxyl group and carbonyl oxygen of the carboxyl group. Compounds 1 and 4 form one more IHB that contribute to the stability of these molecules. The oxygen atoms of the carbonyl and hydroxyl groups possess the lone electrons located in the antibonding orbitals. These lone pair-antibonding orbital interactions, between the oxygen and the adjacent $\mathrm{O}-\mathrm{H}$ bonds, are responsible, as revealed by the NBO analysis, for IHB formation. The energy values presented in Tables S1S6 confirm that the most stable rotamers are those with the highest number of IHBs, especially the ones that include IHBs with carbonyl oxygen. Also it is evident from Figure 2 that compounds $\mathbf{4}$ and $\mathbf{6}$ are symmetrical molecules. In further discussion only the species generated from the most stable rotamers will be discussed.

3.1. Radicals and Anions of DHBAs. Investigation of the antioxidant activity of DHBs was conducted to the $\mathrm{OH}$ groups. This restriction to the $\mathrm{OH}$ groups is supported by the fact that the protons of hydroxyl groups are more acidic than the proton of carboxylic group [53, 54]. The homolytic breaking of the $\mathrm{O}-\mathrm{H}$ bonds in DHBAs results in formation of the radicals (Figure 3). The stability of the formed radicals, in water, plays the main role in determining the antioxidant activity of the investigated molecules. The obtained values of BDE are given in Tables 1 and 2.

The stability of the formed radicals in water is decreasing in the following order: $\mathbf{3}>\mathbf{5}>\mathbf{1}>\mathbf{4}>\mathbf{6}>\mathbf{2}$, while the order in pentylethanoate and benzene is $5>3>1>6>4>2$. This result implies the homolytic cleavage of the $5-\mathrm{OH}$ bond, in the polar solvent, as the favoured one in compound $\mathbf{3}$, 


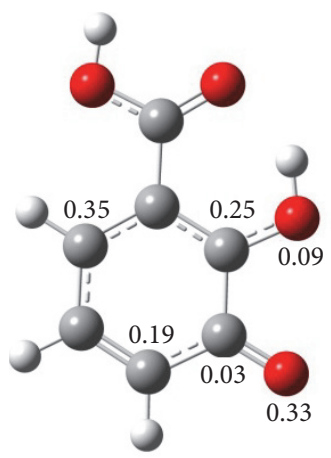

1-R3

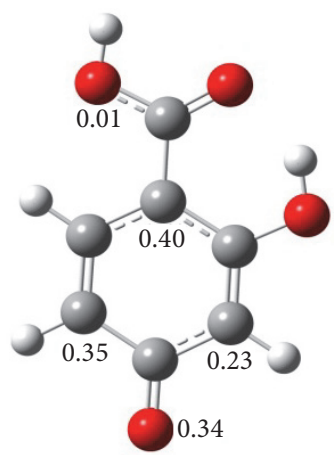

2-R4

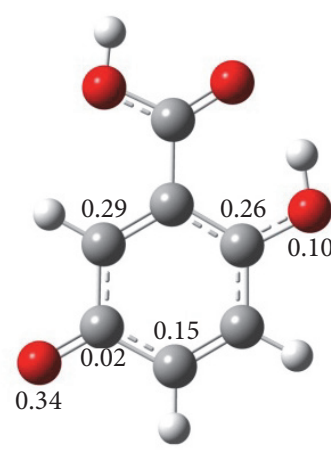

3-R5

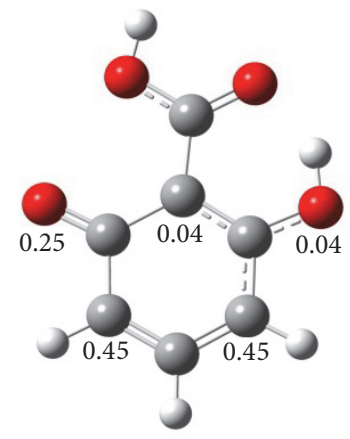

4-R6
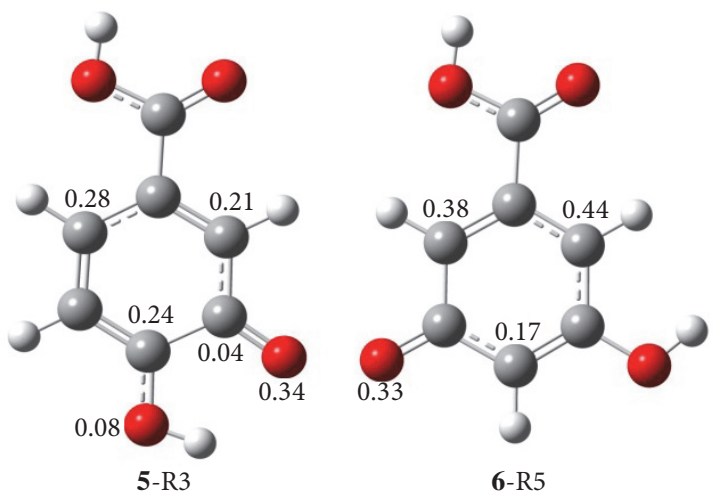

Figure 3: Spin density distribution in all DHBA's radicals in water.

meaning that the 3-R5 radical is the most stable radical of the investigated compounds. On the other hand, the homolytic cleavage of the $3-\mathrm{OH}$ bond, in nonpolar solvents, is the favoured one in compound 5 (5-R3).

In order to rationalise the differences in $\mathrm{BDE}$ and consequently the differences in the reactivity of the individual $\mathrm{OH}$ sites the assessment of the spin density distribution was undertaken on the DHBA's radicals. The lower BDE values implicate easier formation of the radicals and more delocalized spin density [55]. The spin density values in water, obtained by the NBO analysis, as well as SOMOs of DHBAs are depicted in Figures 3 and S7. The results show that the radicals formed from compounds $\mathbf{3}, \mathbf{5}$, and $\mathbf{1}$ are the most stable. This is consequence of delocalization of their unpaired electrons over oxygen and carbons $(\mathrm{O} 5, \mathrm{C} 2, \mathrm{C} 4$, and $\mathrm{C} 6$ in 3-R5; O3, C2, C4, and $\mathrm{C} 6$ in 5-R3; and $\mathrm{O} 3, \mathrm{C} 2, \mathrm{C} 4$, and $\mathrm{C} 6$ in 1-R3). The unpaired electron of 5-R3 can be additionally delocalized only over the one adjacent $\mathrm{OH}$ group, 4-OH (Figure 3). Also, the unpaired electrons are well delocalized in radicals obtained by the homolytic cleavage of the $\mathrm{O}-\mathrm{H}$ bond in other compounds $(\mathbf{2}, \mathbf{4}$, and $\mathbf{6})$.

The heterolytic cleavage of the $\mathrm{O}-\mathrm{H}$ bond results in forming the corresponding anions. The obtained PA values of all $\mathrm{OH}$ groups (in compounds 1-6), as well as in all solvents under investigation, presented in Tables 1 and 2, follow the sequence 5-A4 $>2$-A $4>1-A 2>4-A 6>6-A 5>$ 3-A5. This result implicates the proton transfer from the 4$\mathrm{OH}$ group of the compound $\mathbf{5}$ as easier than the transfer from the other $\mathrm{OH}$ groups. It should be noted that the obtained PA values are significantly lower in water (polar solvent) than the other two, nonpolar, solvents (benzene and pentylethanoate). The reason for this is change of the solvent polarity, which influences the increase of PA values as the solvent polarity increases. This is a consequence of the higher solvation enthalpy of protons.

The natural charge distributions of all anions, formed by heterolytic cleavage of $\mathrm{O}-\mathrm{H}$ bonds of the DHBAs, are presented in Figure 4. Two, the most stable, anions are obtained by deprotonation of the $\mathrm{O}-\mathrm{H}$ bonds of the para phenolic groups of compounds $\mathbf{2}$ and $\mathbf{5}$. The negative charges, which contribute to the stability of these anions, are delocalized over $\mathrm{O} 4, \mathrm{Cl}, \mathrm{C} 3, \mathrm{C} 5$, and $\mathrm{C} 6$ atoms in 2-A4 and over $\mathrm{O} 4$, $\mathrm{C} 1, \mathrm{C} 2, \mathrm{C} 5$, and $\mathrm{C} 6$ atoms in 5-A4. The deprotonated oxygen atom in 5-A4 forms, with the neighbouring $3 \mathrm{OH}$ group, one hydrogen bond, which causes lower PA value and additionally contributes to the stability of this anion.

3.2. Free Radical Scavenging Mechanisms. As mentioned above, three mechanisms of free radical scavenging activity of DHBAs (HAT, SET-PT, and SPLET) were the subject of this study. Reaction enthalpies related to these mechanisms are calculated using (5)-(7b) and by applying two DFT methods. The values of BDE, PA, and IP are used for the estimation of the preferred mechanisms of the antiradical activity of the investigated DHBAs [56-58]. The species needed to complete the thermodynamic calculations are generated from the most stable conformation of the investigated compounds.

If the calculated values obtained by both theoretical methods (Tables 1 and 2) are compared, it is clear that the thermodynamic parameters calculated using the B3LYP-D2 


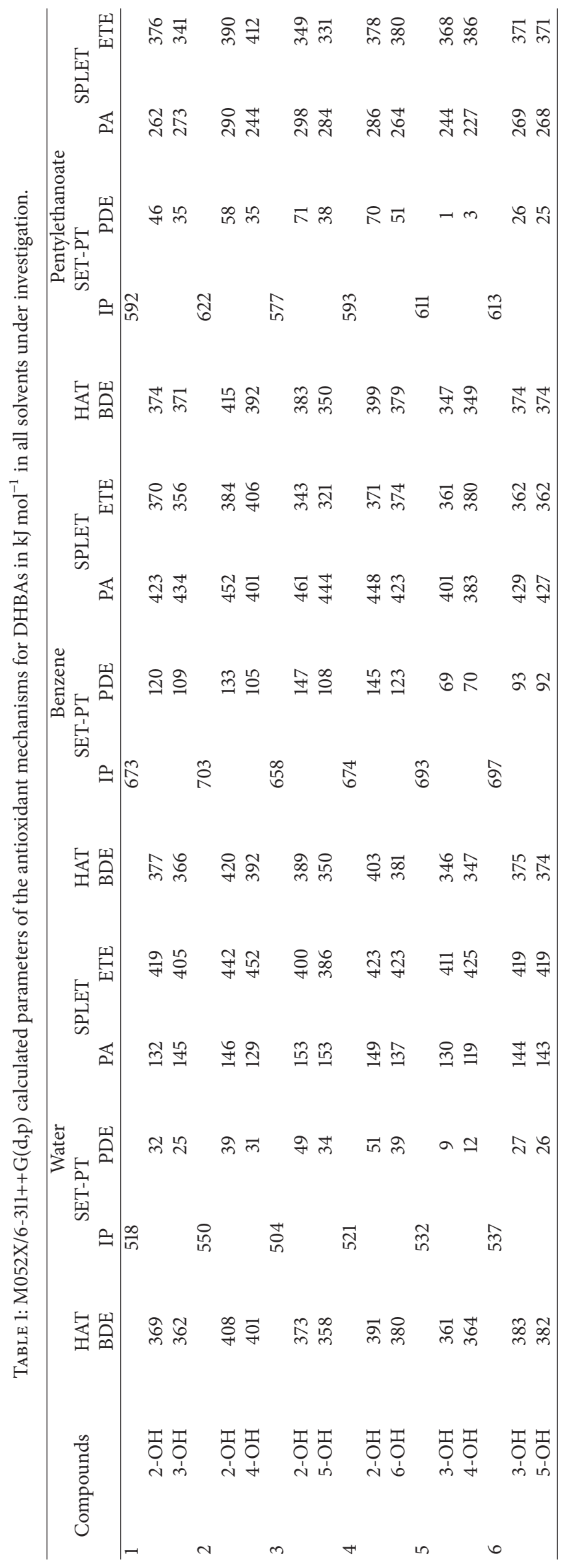




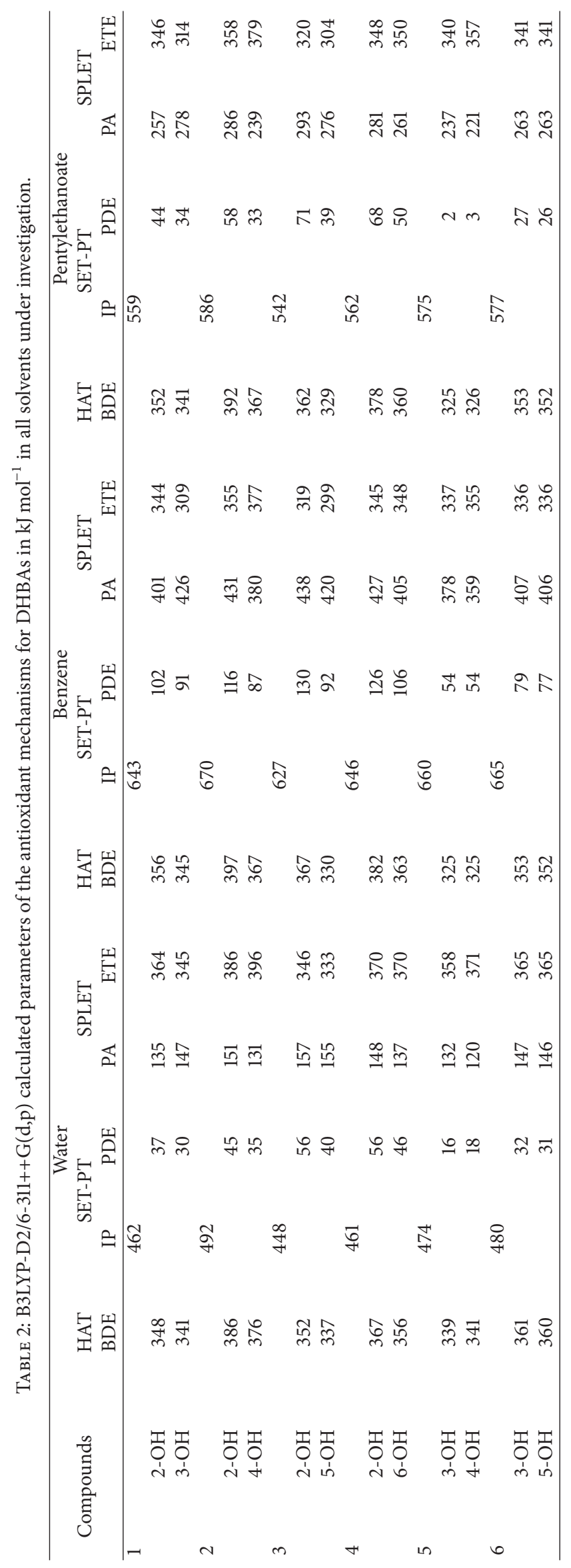




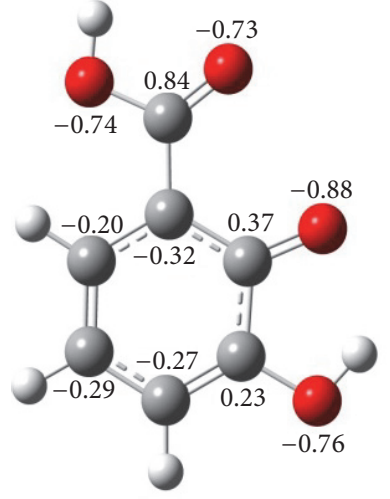

1-A2

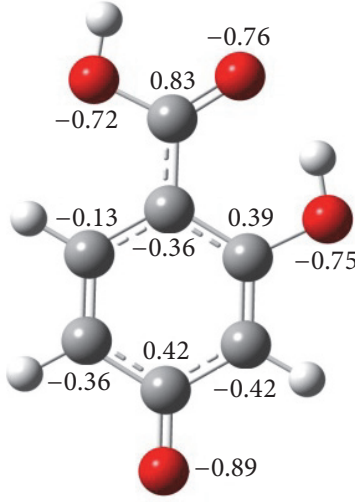

2-A4

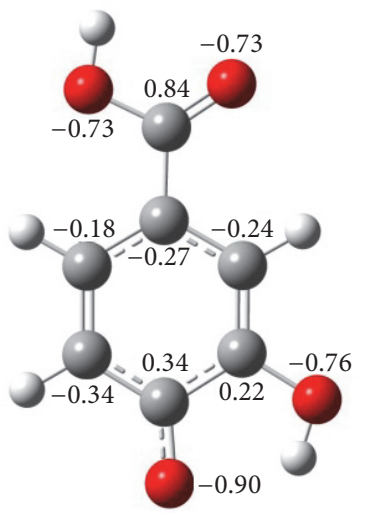

5-A4

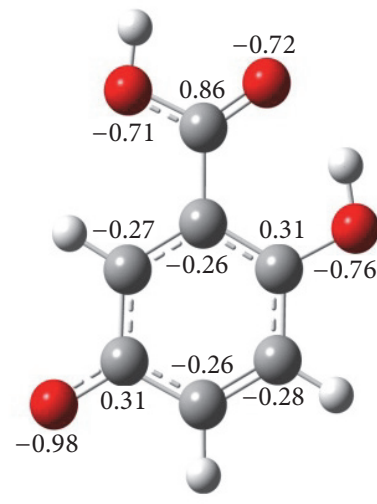

3-A5

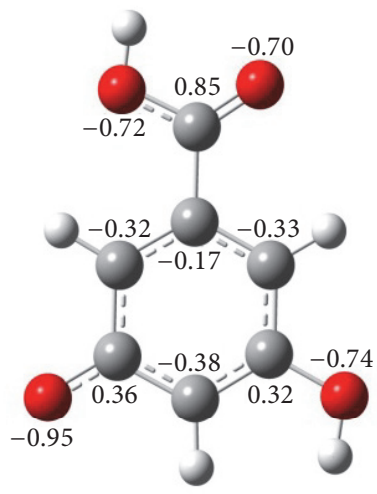

6-A5

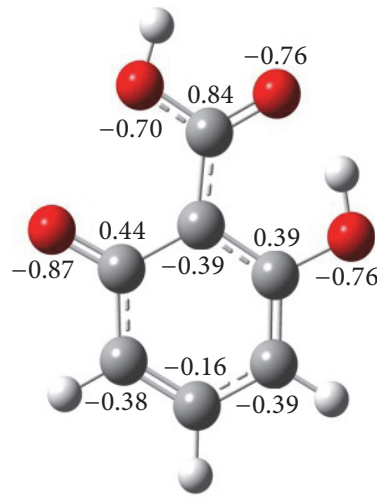

4-A6

FIGURE 4: The natural charge distributions in the most stable anions formed from the investigated DHBAs in water.

functional are mainly lower. Having that in mind, the further discussion will refer to both used methods.

From Tables 1 and 2, it is clear that the IP values for all DHBAs calculated at both theoretical levels, as well as in all solvents investigated, are highly implicating SET-PT as nonoperative mechanism. On the other hand, looking at the obtained results, it is evident that in water and pentylethanoate the PA values are significantly lower than the corresponding BDE values. However, it should be pointed out that PA values are much higher in pentylethanoate than in water which indicates the SPLET mechanism as the most probable reaction pathway in those solvents. Taking into the account BDE and PA values in benzene as classical nonpolar solvent it is evident that BDE values are significantly lower than the corresponding PA values, which proves that the reaction in benzene proceeds via HAT mechanism. Further analysis of the thermodynamic values (Tables 1 and 2) indicates that compounds $\mathbf{5}$ and $\mathbf{1}$ have the best antioxidant activity in all solvents under investigation.

The BDE values obtained for the investigated DHBAs are lower than those for phenol (406.4 and $382.8 \mathrm{~kJ} \mathrm{~mol}^{-1}$ ), resveratrol $\left(368.8\right.$ and $\left.356.2 \mathrm{~kJ} \mathrm{~mol}^{-1}\right)$, and caffeic acid $(359.9$ and $342.52 \mathrm{~kJ} \mathrm{~mol}^{-1}$ ) [59], obtained with B3LYP method in water and benzene, as solvents. Comparing examined dihydroxybenzoic acids with the other phenolic acids, such as hydroxybenzoic acids and gallic acid [40, 41], it is clear that dihydroxybenzoic acids show quite good antioxidative properties. Among all the mentioned acids gallic acid shows the best antioxidant activity proving the significance of the number of hydroxyl groups in such activity [41]. Our results are in good accordance with previous results $[40,41,60]$.

\section{Conclusions}

The generally accepted approach based on the thermodynamic parameters (BDE, IP, and PA), related to the HAT, SPLET, and SET-PT mechanisms, was applied to six dihydroxybenzoic acids, their radicals, and the corresponding radical cations and anions. Calculated energy requirements indicate thermodynamically plausible radical scavenging mechanisms. The calculations performed with two theoretical models, B3LYP-D2 and M05-2X, in polar and nonpolar solvents, proved to be in good accordance.

The obtained results indicate HAT as thermodynamically favourable mechanism in benzene and SPLET in water and pentylethanoate. Calculated energy requirements indicated that compounds $\mathbf{5}$ and $\mathbf{1}$ have better radical scavenging properties than other DHBAs.

\section{Competing Interests}

The authors declare that they have no competing interests. 


\section{Acknowledgments}

The authors gratefully acknowledge the financial support from the Ministry of Science of Republic of Serbia (Projects nos. 172015 and 174028).

\section{References}

[1] B. Halliwell and J. M. C. Gutteridge, Free Radicals in Biology and Medicine, Oxford University Press Inc, New York, NY, USA, 3rd edition, 1999.

[2] I. Fridovich, "The biology of oxygen radicals," Science, vol. 201, no. 4359 , pp. 875-880, 1978.

[3] H. Sies, Oxidative Stress: Oxidants and Antioxidants, Academic Press, New York, NY, USA, 3rd edition, 1991.

[4] C. E. Thomas and B. Kalyanaraman, Oxygen Radicals and the Disease Process, Harwood Academic Publishers, Reading, UK, 1998.

[5] B. Halliwell, "Free radicals and other reactive species in disease," in Encyclopedia of Life Sciences, John Wiley \& Sons, Ltd, Chichester, UK, 2001.

[6] K. Herrmann, "Occurrence and content of hydroxycinnamic and hydroxybenzoic acid compounds in foods," Critical Reviews in Food Science and Nutrition, vol. 28, no. 4, pp. 315-347, 1989.

[7] R. Croteau, T. M. Kutchan, and N. G. Lewis, "Natural products (secondary metabolites)," in Biochemistry \& Molecular Biology of Plants, B. Buchanan, W. Gruissem, and R. Jones, Eds., pp. 1250-1318, American Society of Plant Physiologists, 2000.

[8] M. F. Andreasen, L. P. Christensen, A. S. Meyer, and Å. Hansen, "Content of phenolic acids and ferulic acid dehydrodimers in 17 rye (Secale cereale L.) varieties," Journal of Agricultural and Food Chemistry, vol. 48, no. 7, pp. 2837-2842, 2000.

[9] T. B. T. Lam, K. Kadoya, and K. Iiyama, "Bonding of hydroxycinnamic acids to lignin: ferulic and p-coumaric acids are predominantly linked at the benzyl position of lignin, not the $\beta$-position, in grass cell walls," Phytochemistry, vol. 57, no. 6, pp. 987-992, 2001.

[10] C. Brett and K. Waldron, "Cell wall structure and the skeletal functions of the wall," in Physiology and Biochemistry of Plant Cell Walls, C. Brett and K. Waldron, Eds., pp. 44-74, Chapman and Hall, Dordrecht, the Netherlands, 1996.

[11] H. Wu, T. Haig, J. Pratley, D. Lemerle, and M. An, "Simultaneous determination of phenolic acids and 2,4-dihydroxy-7-methoxy1,4-benzoxazin-3-one in wheat (Triticum aestivum L.) by gas chromatography-tandem mass spectrometry," Journal of Chromatography A, vol. 864, no. 2, pp. 315-321, 1999.

[12] H. Wu, T. Haig, J. Pratley, D. Lemerle, and M. An, "Allelochemicals in wheat (Triticum Aestivum L.): variation of phenolic acids in root tissues," Journal of Agricultural and Food Chemistry, vol. 48, no. 11, pp. 5321-5325, 2000.

[13] F. A. Einhellig, "Mechanisms and modes of action of allelochemicals," in The Science of Allelopathy, A. R. Putnam and C. S. Tang, Eds., pp. 171-189, John Wiley and Sons, New York, NY, USA, 1986.

[14] A. R. Ness and J. W. Powles, "Fruit and vegetables, and cardiovascular disease: a review," International Journal of Epidemiology, vol. 26, no. 1, pp. 1-13, 1997.

[15] R. A. Jacob and B. J. Burri, "Oxidative damage and defense," The American Journal of Clinical Nutrition, vol. 63, no. 6, pp. 985S990S, 1996.
[16] G. Block, B. Patterson, and A. Subar, "Fruit, vegetables, and cancer prevention: a review of the epidemiological evidence," Nutrition and Cancer, vol. 18, no. 1, pp. 1-29, 1992.

[17] M. Huang and T. Ferraro, "Phenolic compounds in food and cancer prevention," in Phenolic Compounds in Food and Their Effects on Health II, vol. 507 of ACS Symposium Series, pp. 8-34, American Chemical Society, Washington, DC, USA, 1992.

[18] S. Z. Dziedzic and B. J. F. Hudson, "Polyhydroxy chalcones and flavanones as antioxidants for edible oils," Food Chemistry, vol. 12, no. 3, pp. 205-212, 1983.

[19] C. A. Rice-Evans, N. J. Miller, and G. Paganga, "Structureantioxidant activity relationships of flavonoids and phenolic acids," Free Radical Biology and Medicine, vol. 20, no. 7, pp. 933956, 1996.

[20] Y.-Z. Cai, M. Sun, J. Xing, Q. Luo, and H. Corke, "Structureradical scavenging activity relationships of phenolic compounds from traditional Chinese medicinal plants," Life Sciences, vol. 78, no. 25, pp. 2872-2888, 2006.

[21] D.-O. Kim and C. Y. Lee, "Comprehensive study on vitamin $\mathrm{C}$ equivalent antioxidant capacity (VCEAC) of various polyphenolics in scavenging a free radical and its structural relationship," Critical Reviews in Food Science and Nutrition, vol. 44, no. 4, pp. 253-273, 2004.

[22] W. G. De Graff, L. S. Myers Jr., J. B. Mitchell, and S. M. Hahn, "Protection against Adriamycin cytotoxicity and inhibition of DNA topoisomerase II activity by 3,4-dihydroxybenzoic acid," International journal of oncology, vol. 23, pp. 159-163, 2003.

[23] C.-Y. Chao and M.-C. Yin, "Antibacterial effects of roselle calyx extracts and protocatechuic acid in ground beef and apple juice," Foodborne Pathogens and Disease, vol. 6, no. 2, pp. 201-206, 2009.

[24] D. Stagos, G. Kazantzoglou, D. Theofanidou et al., "Activity of grape extracts from Greek varieties of Vitis vinifera against mutagenicity induced by bleomycin and hydrogen peroxide in Salmonella typhimurium strain TA102," Mutation Research/Genetic Toxicology and Environmental Mutagenesis, vol. 609, no. 2, pp. 165-175, 2006.

[25] C.-Y. Lin, C.-S. Huang, C.-Y. Huang, and M.-C. Yin, "Anticoagulatory, antiinflammatory, and antioxidative effects of protocatechuic acid in diabetic mice," Journal of Agricultural and Food Chemistry, vol. 57, no. 15, pp. 6661-6667, 2009.

[26] Y.-I. I. Kwon, D. A. Vattem, and K. Shetty, "Evaluation of clonal herbs of Lamiaceae species for management of diabetes and hypertension," Asia Pacific Journal of Clinical Nutrition, vol. 15, no. 1, pp. 107-118, 2006.

[27] K. Prasad and V. A. Laxdal, "Hydroxyl radical-scavenging property of indomethacin," Molecular and Cellular Biochemistry, vol. 136, no. 2, pp. 139-144, 1994.

[28] T. D. H. Bugg, "Dioxygenase enzymes: catalytic mechanisms and chemical models," Tetrahedron, vol. 59, no. 36, pp. 70757101, 2003.

[29] J. M. Mayer, "Proton-coupled electron transfer: a reaction chemist's view," Annual Review of Physical Chemistry, vol. 55, pp. 363-390, 2004.

[30] M. H. V. Huynh and T. J. Meyer, "Proton-coupled electron transfer," Chemical Reviews, vol. 107, no. 11, pp. 5004-5064, 2007.

[31] Z. S. Marković, J. M. D. Marković, and Ć. B. Doličanin, "Mechanistic pathways for the reaction of quercetin with hydroperoxy radical," Theoretical Chemistry Accounts, vol. 127, no. 1, pp. 6980, 2010. 
[32] S. G. Chiodo, M. Leopoldini, N. Russo, and M. Toscano, "The inactivation of lipid peroxide radical by quercetin. A theoretical insight," Physical Chemistry Chemical Physics, vol. 12, no. 27, pp. 7662-7670, 2010.

[33] G. Litwinienko and K. U. Ingold, "Solvent effects on the rates and mechanisms of reaction of phenols with free radicals," Accounts of Chemical Research, vol. 40, no. 3, pp. 222-230, 2007.

[34] J. S. Wright, E. R. Johnson, and G. A. DiLabio, "Predicting the activity of phenolic antioxidants: theoretical method, analysis of substituent effects, and application to major families of antioxidants," Journal of the American Chemical Society, vol. 123, no. 6, pp. 1173-1183, 2001.

[35] E. Klein and V. Lukeš, "DFT/B3LYP study of the substituent effect on the reaction enthalpies of the individual steps of single electron transfer-proton transfer and sequential proton loss electron transfer mechanisms of phenols antioxidant action," The Journal of Physical Chemistry A, vol. 110, no. 44, pp. 1231212320, 2006.

[36] G. A. DiLabio and K. U. Ingold, "A theoretical study of the iminoxyl/oxime self-exchange reaction. A five-center, cyclic proton-coupled electron transfer," Journal of the American Chemical Society, vol. 127, no. 18, pp. 6693-6699, 2005.

[37] M. J. Frisch, G. W. Trucks, H. B. Schlegel et al., Gaussian 09, Revision D.01, Gaussian, Wallingford, Conn, USA, 2009.

[38] Y. Zhao, N. E. Schultz, and D. G. Truhlar, "Exchange-correlation functional with broad accuracy for metallic and nonmetallic compounds, kinetics, and noncovalent interactions," Journal of Chemical Physics, vol. 123, no. 16, Article ID 161103, 2005.

[39] A. D. McLean and G. S. Chandler, "Contracted Gaussian basis sets for molecular calculations. I. Second row atoms, $\mathrm{Z}=11-18$," The Journal of Chemical Physics, vol. 72, no. 10, pp. 5639-5648, 1980.

[40] Z. Marković, J. Dorović, J. M. Dimitrić Marković, R. Biočanin, and D. Amić, "Comparative density functional study of antioxidative activity of the hydroxybenzoic acids and their anions," Turkish Journal of Chemistry, vol. 40, no. 3, pp. 499-509, 2016.

[41] J. Đorović, J. M. D. Marković, V. Stepanić, N. Begović, D. Amić, and Z. Marković, "Influence of different free radicals on scavenging potency of gallic acid," Journal of Molecular Modeling, vol. 20, article 2345, 2014.

[42] G. Black and J. M. Simmie, "Barrier heights for H-atom abstraction by $\mathrm{HO}_{2}$ from n-butanol-a simple yet exacting test for model chemistries?" Journal of Computational Chemistry, vol. 31, no. 6, pp. 1236-1248, 2010.

[43] A. Galano, N. A. Macías-Ruvalcaba, O. N. M. Campos, and J. Pedraza-Chaverri, "Mechanism of the $\mathrm{OH}$ radical scavenging activity of nordihydroguaiaretic acid: a combined theoretical and experimental study," Journal of Physical Chemistry B, vol. 114, no. 19, pp. 6625-6635, 2010.

[44] M. E. Alberto, N. Russo, A. Grand, and A. Galano, "A physicochemical examination of the free radical scavenging activity of Trolox: mechanism, kinetics and influence of the environment," Physical Chemistry Chemical Physics, vol. 15, no. 13, pp. 46424650, 2013.

[45] S. Grimme, "Semiempirical GGA-type density functional constructed with a long-range dispersion correction," Journal of Computational Chemistry, vol. 27, no. 15, pp. 1787-1799, 2006.

[46] S. Grimme, "Density functional theory with London dispersion corrections," Wiley Interdisciplinary Reviews: Computational Molecular Science, vol. 1, no. 2, pp. 211-228, 2011.
[47] A. D. Becke, "Density-functional thermochemistry. III. The role of exact exchange," The Journal of Chemical Physics, vol. 98, no. 7, pp. 5648-5652, 1993.

[48] C. Lee, W. Yang, and R. G. Parr, "Development of the ColleSalvetti correlation-energy formula into a functional of the electron density," Physical Review B, vol. 37, no. 2, pp. 785-789, 1988.

[49] I. Bayach, J. C. Sancho-García, F. Di Meo, J.-F. F. Weber, and P. Trouillas, " $\pi$-Stacked polyphenolic dimers: a case study using dispersion-corrected methods," Chemical Physics Letters, vol. 578, pp. 120-125, 2013.

[50] A. V. Marenich, C. J. Cramer, and D. G. Truhlar, "Universal solvation model based on solute electron density and on a continuum model of the solvent defined by the bulk dielectric constant and atomic surface tensions," Journal of Physical Chemistry B, vol. 113, no. 18, pp. 6378-6396, 2009.

[51] A. E. Reed, L. A. Curtiss, and F. Weinhold, "Intermolecular interactions from a natural bond orbital, donor-acceptor viewpoint," Chemical Reviews, vol. 88, no. 6, pp. 899-926, 1988.

[52] Z. Marković, D. Milenković, J. Dorović, and S. Jeremić, "Solvation enthalpies of the proton and electron in polar and nonpolar solvents," Journal of the Serbian Society for Computational Mechanics, vol. 7, no. 2, pp. 1-9, 2013.

[53] M. E. Gimon, L. M. Preston, T. Solouki, M. A. White, and D. H. Russell, "Are proton transfer reactions of excited states involved in UV laser desorption ionization?" Organic Mass Spectrometry, vol. 27, no. 7, pp. 827-830, 1992.

[54] F. H. Yassin and D. S. Marynick, "Computational estimates of the gas-phase acidities of dihydroxybenzoic acid radical cations and their corresponding neutral species," Journal of Molecular Structure: THEOCHEM, vol. 629, pp. 223-235, 2003.

[55] Z. S. Marković, J. M. Dimitrić-Marković, D. Milenković, and N. Filipović, "Structural and electronic features of baicalein and its radicals," Monatshefte fur Chemie-Chemical Monthly, vol. 142, no. 2, pp. 145-152, 2011.

[56] E. Klein, V. Lukeš, and M. Ilčin, "DFT/B3LYP study of tocopherols and chromans antioxidant action energetics," Chemical Physics, vol. 336, no. 1, pp. 51-57, 2007.

[57] J. Rimarčík, V. Lukeš, E. Klein, and M. Ilčin, "Study of the solvent effect on the enthalpies of homolytic and heterolytic N-H bond cleavage in p-phenylenediamine and tetracyano-p-phenylenediamine," Journal of Molecular Structure: THEOCHEM, vol. 952, no. 1-3, pp. 25-30, 2010.

[58] A. Vagánek, J. Rimarčík, V. Lukeš, and E. Klein, "On the energetics of homolytic and heterolytic $\mathrm{OH}$ bond cleavage in flavonoids," Computational and Theoretical Chemistry, vol. 991, pp. 192-200, 2012.

[59] M. Leopoldini, T. Marino, N. Russo, and M. Toscano, "Antioxidant properties of phenolic compounds: $\mathrm{H}$-atom versus electron transfer mechanism," Journal of Physical Chemistry A, vol. 108, no. 22, pp. 4916-4922, 2004.

[60] A. Pérez-González, A. Galano, and J. R. Alvarez-Idaboy, "Dihydroxybenzoic acids as free radical scavengers: mechanisms, kinetics, and trends in activity," New Journal of Chemistry, vol. 38 , no. 6, pp. 2639-2652, 2014. 

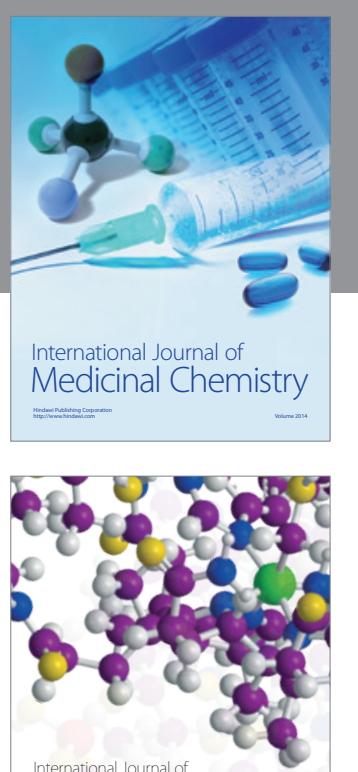

Carbohydrate Chemistry

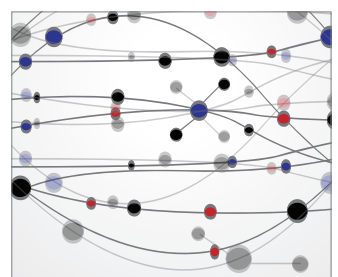

The Scientific World Journal
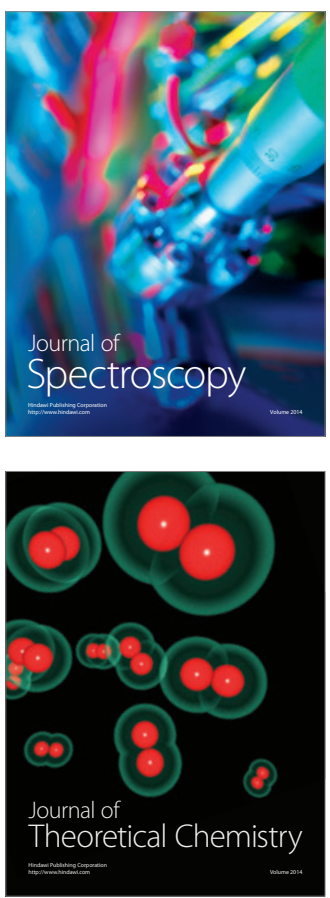
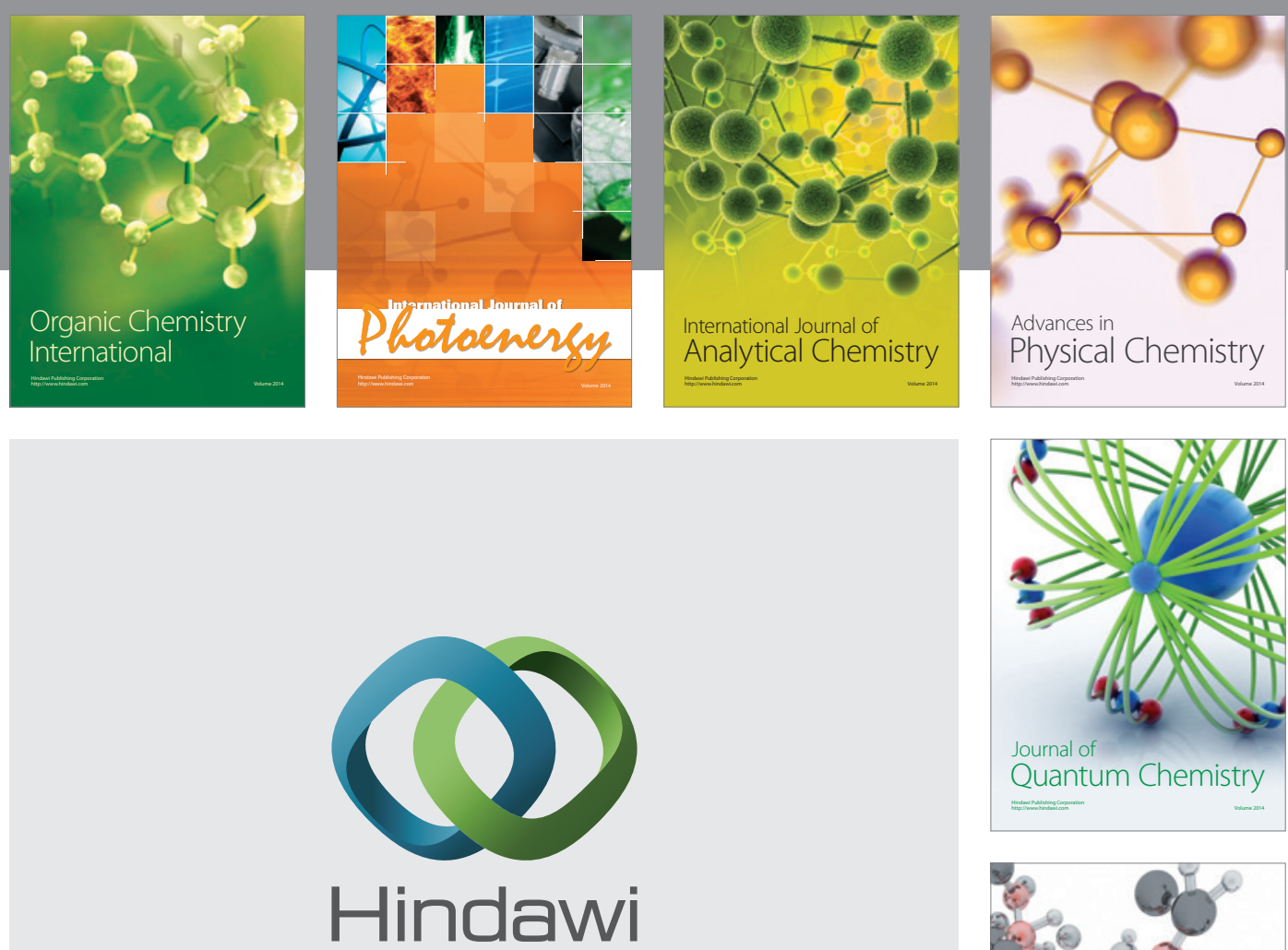

Submit your manuscripts at

https://www.hindawi.com

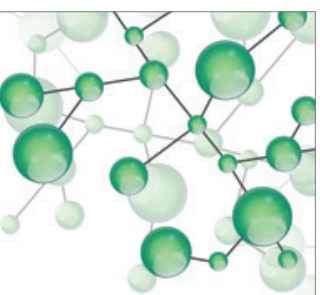

International Journal of

Inorganic Chemistry
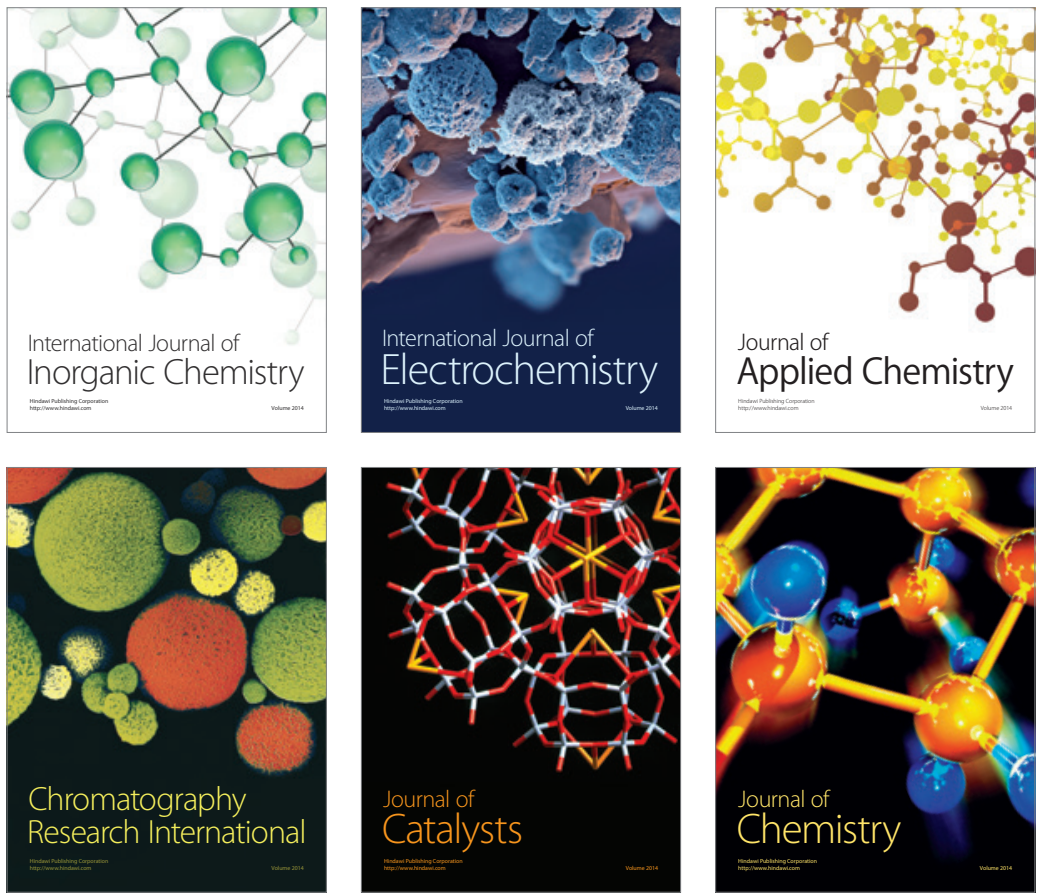

Journal of

Applied Chemistry
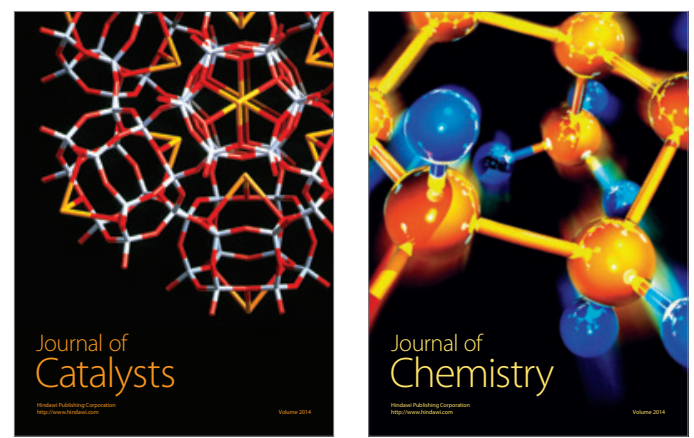
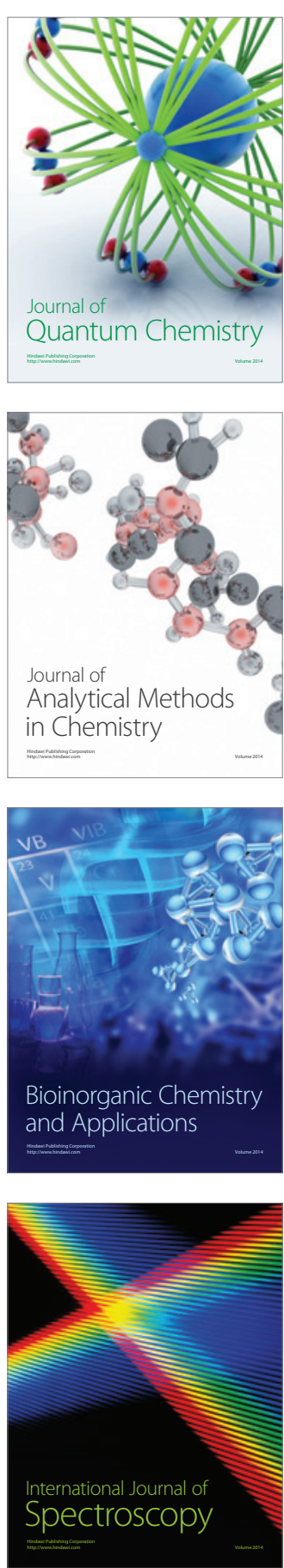